\title{
Remote Sensing in Social Science Research
}

\author{
Ola Hall* \\ GIS-centrum, Department of Earth and Ecosystem Sciences, Division of Physical Geography and Ecosystems Analysis, \\ Lund university, Sölvegatan 12, 22362 Lund, Sweeden
}

\begin{abstract}
Since the early days of satellite remote sensing in the 1950's, accessibility, quality, and scope of remote sensing image data has been continuously improving, making it a rich data source with a wide range of applications. Today, the use of remote sensing techniques and data is commonplace within many disciplines in the natural sciences. Although there are quite a few examples of remote sensing to be found in the social sciences, developments here have, on the whole, been less pronounced. This paper investigates 1) how remote sensing data has been put to use in social science studies, and 2) how social science could better utilize the huge potential of remote sensing data. The first part of the paper gives an overview of existing types of remote sensing techniques and data collection. The second part consistsof a review of social science applications of remote sensing data. In the conclusions it is argued that remote sensing data is at its most valuable in the social sciences when used in combination with traditional methods such as surveys, public records, interviews and direct observation.
\end{abstract}

Keywords: Social science, remote sensing, land-cover, urban, census.

\section{INTRODUCTION}

Since 1858, when the journalist and pioneering photographer Félix Nadar (1820-1910) decided to photograph Paris from an air balloon, remote sensing has been of fundamental importance for civil and military surveying and reconnaissance. From 1909 and onwards, airplanes have been used for aerial photography missions and during first world war cameras were specially constructed for aerial photography [1]. During the late 1950s, US military CORONA satellites, equipped with cameras for undetected reconnaissance, photographed large areas of foreign territories. In 1995, President Clinton ordered the declassification of more than 800, 000 images collected between 1960-1972 by these satellites.

Since these early days of satellite remote sensing the availability and quality of image data has been continuously improving. Today, remote sensing data is widely acknowledged and applications are found in many areas of society. Weather forecasting, monitoring of forestry and agricultural activities, disaster management, or simply as a complement to other digital services are but a few applications. Many organizations provide and distribute satellite data free of charge. For example, the Global Land Cover Facility http://glcf.umiacs.umd.edu/index.shtml) and the Swedish national satellite database Saccess (http://saccess.lantmateriet.se/) offer state-of-the-art imagery via open access websites.

*Address correspondence to this author at the GIS-centrum, Department of Earth and Ecosystem Sciences, Division of Physical Geography and Ecosystems Analysis, Lund university, Sölvegatan 12, 22362 Lund;, Sweeden; TellFax: +46(0)733-747849; E-mail: Ola.hall@nateko.lu.se
Remote sensing applications are commonplace in many research programmes in the natural and environmental sciences. It is a valuable source for data on vegetation composition and structure, and is used in landscape ecology, biology, physical geography, etc.

The central topic of this paper is the use of remote sensing in the social sciences, where the practice of using remote sensing data is less developed. The aim of this paper is to review research in remote sensing based social science. Earlier efforts with similar scope exist. Most noticeable is probably the 1998 publication from the National Research Council, "People and Pixels: Linking Remote Sensing and Social Sciences" which summarized research in the human dimensions of global change in a series of essays during the first half of the 1990s [2]. In addition, CIESIN (Center for International Earth Science Information Network) has compiled an unpublished report "Social Science Applications of Remote Sensing" that covers a wide range of issues up until the year 2000 [3]. Most literature found in this text is compiled from individual papers encompassing a wide spectrum of scientific journals. Due to the cross-disciplinary character of research in this realm, papers are rarely published in "pure" remote sensing literature, or in "pure" social science journals. Instead, much of the work presented here was found in journals specializing in "Sustainability science" or "Global change studies", which is an interesting observation in itself.

This paper is structured in three main sections; the first provides an overview and introduction to remote sensing fundamentals and is directed at readers not already familiar with remote sensing technology. The second section of this paper concerns the applications of remote sensing in social science research, whilst the third section presents 
conclusions derived from the first two. A comprehensive bibliography is appended.

\subsection{Definitions}

Remote sensing is the science, technology, and art of obtaining information on objects from a distance. It allows identification and classification of objects according to type and spatial distribution [4]. Typically, remote sensing relies on measurements of electromagnetic energy emitted by or reflected from the features of interest. Measurements are normally made by analog or digital sensors mounted on satellites, airplanes, or some other airborne vehicle. Digital cameras, the human visual system and ground based detectors are all examples of those technical and biological systems which exhibit similar characteristics to a remote sensing system, when applied to the gathering information about objects from a distance. Here, we focus on the application of optical remote sensing from airplanes or satellites, which makes use of visible, near infrared and short-waveinfrared sensors to form images of the earth's surface. Only in brief we will consider radar and lidar remote sensing.

Numerous examples exist where remote sensing has been employed for socially useful purposes, but there are few examples of remote sensing within the context of social scientific research [3]. Only the latter will be addressed here. The social sciences can be defined as those academic disciplines concerned with the study of society and the social life of human groups and individuals; it includes anthropology, economics, geography, history, political science, psychology, social studies, and sociology. Research that utilizes remote sensing data is seldom in the mainstream of the particular discipline and therefore, publications are usually found in topic-oriented journals, not disciplineoriented. Research is often conducted under the umbrella of meta-disciplines, e.g. "land-change science" and "sustainability science". Sometimes it can be quite difficult to decide if a certain application qualifies as "social science". However, the guiding principle has been that attention be paid to the social, economical or cultural dimension of the particular study.

\section{REMOTE SENSING FUNDAMENTALS}

The aim of this section is to provide the readers that are new to remote sensing with a technical background. The content is primarily based on [5] and [6]. This section is divided as follows: Physical Principles, which describes the electromagnetic spectrum and provide some definitions of key terminology, Satellite Sensors, which describe the characteristics of common remote sensing systems, and finally Image Analysis, which provide a background to standard processing techniques.

\subsection{Physical Principles}

The first requirement for remote sensing is to have an energy source which illuminates or provides the target of interest with electromagnetic energy. Electromagnetic radiation has a predictable physical behavior described by wave theory. Wavelength and frequency are fundamental charac-teristics of electromagnetic radiation and are of particular interest in remote sensing. The wavelength is the length of one wave cycle, representing the distance between successive wave crests. Wavelength is usually represented by the Greek letter lambda $(\lambda)$. The frequency refers to the number of cycles of a wave passing a fixed point per unit of time. Frequency is normally measured in hertz $(\mathrm{Hz})$, describing the number ofcycles per second. Frequency and wavelength are inversely related to each other, meaning, the longer the wavelength, the shorter the frequency and vice versa.

The electromagnetic spectrum is categorized according to wavelength and frequency. The shorter wavelength end of the spectrum includes x-rays, whilst the longer wavelengths include microwaves and radio waves (Fig. 1). The part of the electromagnetic spectrum visible to the human eye is small and covers the approximate range 0.4 to $0.7 \mu \mathrm{m}$. The longest visible wavelength is red and the shortest is violet. There are several regions of the electromagnetic spectrum which are useful for remote sensing. The ultraviolet (UV) portion of the spectrum has short wavelengths. When rocks and minerals are illuminated with UV-radiation they emit visible light. The infrared (IR) portion of the spectrum covers the approximaterange $0.7 \mu \mathrm{m}$ to $100 \mu \mathrm{m}$ and can be divided into thermal IR and reflected IR. Thermal IR is the heat that is emitted from objects on Earth. Any object with a temperature above 0 Kelvin emits thermal radiation. In more recent times, remote sensing has utilized longer wavelength microwave radiation, with $\lambda$ values in the range $1 \mathrm{~mm}$ to 1 $\mathrm{m}$. Before the radiation used in remote sensing reaches Earth it passes through the atmosphere. Here, radiation can be either scattered or absorbed. In both cases, less of the radiation than originally emitted reaches the target. The degree of atmospheric penetration of different parts of the electromagnetic spectrum is dependent on wavelength and atmospheric content (green house gases, vapor, particles, etc). In some portions of the spectrum, almost all radiation is absorbed and consequently no radiation reaches the Earth's surface, rendering remote sensing impossible. Those portions of the electromagnetic spectrum where radiation transmission through the atmosphere is high are called atmospheric windows and are most useful for remote sensing purposes. The visible portion of the spectrum is one obvious atmospheric window.

A target can reflect, absorb, or transmit the incoming radiation. Transmission occurs when radiation passes through a target while absorption occurs when energy is absorbed by the target. Reflection results when the radiation is bouncing off the surface in question and is, for remote sensing purposes, the most interesting type of target interaction. Reflection can be of the specular kind, where the target surface is smooth and acts like a mirror, redirecting all the energy in one direction. However, when a target surface is rough, the radiation is reflected in all directions.

When the reflected energy is measured over a variety of different wavelengths a spectral response pattern for that target can be recorded. By comparing the spectral response patterns of different objects, it is possible to identify spatial separation and distinguish different objects from one another. It is common for different objects to have similar spectral responses in certain parts of the electromagnetic spectrum, but when several wavelengths are compared, objects can usually be resolved. This is a fundamental observation in remote sensing image analysis. 


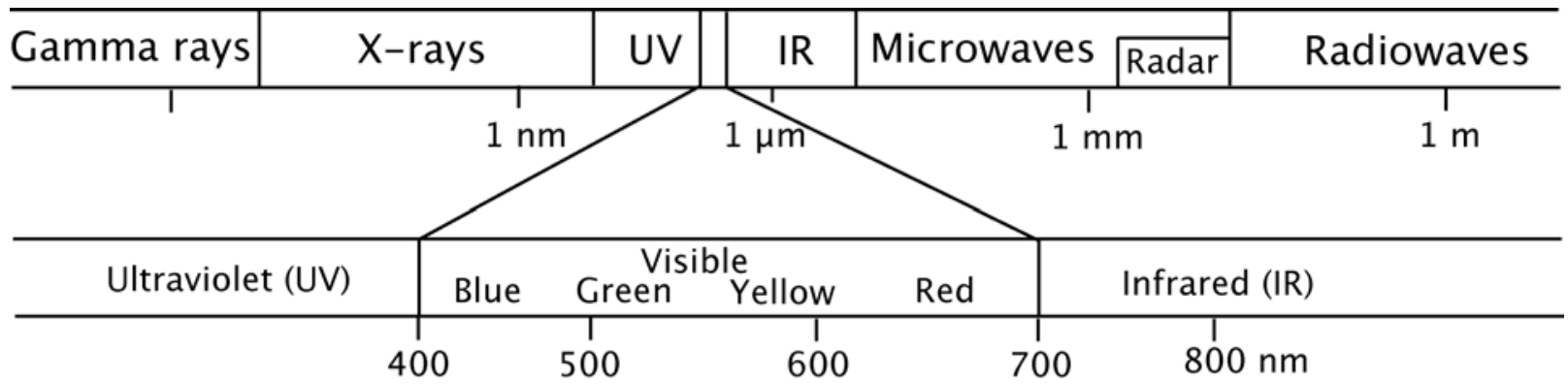

Fig. (1). The electromagnetic spectrum.

\subsection{Satellite Sensors}

Remote sensing systems, which measure energy that is naturally available, are called passive sensors. Passive sensors can only be used to detect energy when this naturally occurring energy is available. In the case of all reflected energy, this can only take place when the sun is illuminating the Earth. Energy that is naturally emitted (such as thermal infrared) can be detected day or night, as long as the amount of energy is large enough to be recorded. Active sensors, on the other hand, provide their own energy source for illumination. The sensor emits radiation which is directed toward the target under investigation. The radiation reflected from that target is then detected and measured by the sensor. The advantages of active sensor include the ability to obtain measurementsregardless of the time of day or season. Active sensors can also be used for examining wavelengths that are not provided in sufficient strengthby the sun, such as microwaves. In addition, active sensors offer better control over the way a target is illuminated. Some examples of active sensors include LIDAR (Light Detection and Ranging) and Synthetic Aperture Radar (SAR). LIDAR is an optical active sensor that measures the properties of scattered light and can be used to calculate properties of a distant target. The prevalent method to determine the distance to an object or surface is the use of laser pulses. Similarly, through using radar (Radio Detection and Ranging) technology, employing light that is not in the visible part of the spectrum, the range to an object can be determined by measuring the time delay between the transmission of a pulse and the detection of the reflected signal.

Many electronic remote sensors acquire data using scanning systems, which employ a sensor with a narrow field of view that sweeps over the terrain to build up and produce a two-dimensional image of the surface. A scanning system used to collect data over a variety of different wavelength ranges is called a multispectral scanner and is the most commonly used scanning system. The detail discernible in an image is dependent on the spatial resolution of the sensor and refers to the size of the smallest possible feature that can be detected. Spatial resolution of passive sensors depends primarily on their Instantaneous Field of View (IFOV). The IFOV is the angular cone of visibility of the sensor and determines the area on the Earth's surface which is "seen" at one particular moment in time from a given altitude. The size of the area viewed is determined by multiplying the IFOV by the distance from the ground to the sensor. This calculated ground area is called the resolution cell and determines a sensor's maximum spatial resolution. For a homogeneous feature to be detected, its size generally has to be equal to or larger than the resolution cell. If the feature is smaller than this, it may not be detectable as the average brightness of all features within that resolution cell will be recorded. However, smaller features may sometimes be detectable if their reflectance dominates within a particular resolution cell, allowing sub-pixel or resolution cell detection. The finer the resolution, the less total ground area that can be seen.

Spectral resolution describes the ability of a sensor to define fine wavelength intervals. The finer the spectral resolution, the narrower the wavelength range for a particular channel or band. Many remote sensing systems record energy over several separate wavelength ranges at various spectral resolutions. These are referred to as multi-spectral sensors and hyperspectral sensors and detect hundreds of very narrow spectral bands in the visible, near-infrared, and mid-infrared portions of the electromagnetic spectrum.

The radiometric resolution of an imaging system describes its ability to discriminate very slight differences in energy. The finer the radiometric resolution of a sensor, the more sensitive it is to detecting small differences in reflected or emitted energy. When resolution of any kind is increased, data volumes and consequently processing time is increased.

The number of remote sensing sensors producing Earth surface information is large and is increasing rapidly. Most applications in the social sciences rely on Landsat data, although applications using SPOT, IKONOS and others are becoming more frequent. Hyperspectral data is very rare, as are active sensor data such as SAR or LIDAR. The popularity of Landsat data is attributed to the use of a combination of sensors with spectral bands tailored to Earth observation, functional spatial resolution, good areal coverage, and because the long lifespan of the program has provided a voluminous archive of Earth resource data. The latter has allowed long term monitoring and research, and has facilitated the creation of historical records. Most of the historical and also recent data are freely available from sites like http://landsat.gsfc.nasa.gov/ and http://landsat.usgs.gov/

Landsat-1 was the first satellite designed specifically to monitor the Earth's surface and was launched by NASA in 1972. In 1985 the Landsat program became commercialized. The Landsat series of satellites carry a number of on board sensors, which have been progressively improved, giving greater spatial, spectral and radiometric resolution (see Table 1 and 2). 
Table 1. Landsat Mission Characteristics. Based on [5]

\begin{tabular}{|c|c|c|c|c|c|c|}
\hline \multirow[b]{2}{*}{ Satellite } & \multirow[b]{2}{*}{ Launch } & \multirow[b]{2}{*}{ Ended } & \multicolumn{3}{|c|}{ Bands } & \multirow{2}{*}{$\begin{array}{c}\text { Orbit } \\
\text { Days/km }\end{array}$} \\
\hline & & & RBV & MSS & TM & \\
\hline Landsat-1 & July, 23, 1972 & Jan 6,1978 & $1-3$ & $4-7$ & None & $18 / 900$ \\
\hline Landsat-2 & Jan 22, 1975 & Feb 25, 1982 & $1-3$ & $4-7$ & None & $18 / 900$ \\
\hline Landsat- 4 & July $16,1982^{b}$ & - & None & $1-4$ & $1-7$ & $16 / 705$ \\
\hline Landsat-5 & March 1, 1984 & - & None & $1-4$ & $1-7$ & $16 / 705$ \\
\hline Landsat- 6 & Oct 5, 1993 & Failed launch & None & None & 1-7, ETM & $16 / 705$ \\
\hline Landsat-7 & April 15, 1999 & - & None & None & 1-7, ETM+ & $16 / 705$ \\
\hline
\end{tabular}

${ }^{\mathrm{a}}$ Band 8 failed shortly after launch, ${ }^{\mathrm{b}}$ TM data transmission failed in August 1993.

The MSS and TM sensors have collected data over a swath width of $185 \mathrm{~km}$, with the full scene being $185 \mathrm{~km} \mathrm{x}$ $185 \mathrm{~km}$. MSS sensed electromagnetic radiation is collected in four spectral bands, with a nominal spatial resolution of $60 \times 80$ meters. Collection of MSS data stopped in 1992, following the introduction ofaTM sensoronboard the Landsat-4 satellite. This TM sensor offered several improvements over the MSS sensor. The spatial resolution was increased to $30 \mathrm{~m}$ and 120 for thermal IR. The number of spectral bands was increased from 4 to 7 and the radiometric resolution was improved, from 6 bits to 8 bits.

SPOT (Système Pour l'Observation de la Terre) is a series of Earth observation imaging satellites designed and launched by CNES (Centre National d'Études Spatiales) of France, with support from Sweden and Belgium (Table 3). The program was commercially oriented and was meant to be operational, rather than experimental, as was the case with the Landsat program. The first satellite was launched in 1986 and was equipped with a number of innovations including pointable optics. The fact that the onboard optics were designed to be pointable enabled side-to-side viewing capabilities and full-scene stereoscopic imaging. By recording the same area from two different angles, the imagery can be viewed and analyzed as a three dimensional model, which is of great value for terrain analysis, mapping and visualization.

If Landsat is associated with forest applications, then SPOT is typically associated with applications wherefine spatial detail must be resolved, such as urban mapping. An interesting capability of SPOT is that the high-resolution panchromatic band can be used to sharpen the spatial detail in the multispectral bands.

Numerous systems have been launched, or are in development phases, that achieve much higher resolution than Landsat and SPOT (See Table 4). In 1999, Space Imaging launched the IKONOS system. This is a commercial high-resolution earth observation satellite situated some $682-\mathrm{km}$ above the Earth's surface, with an orbital (revisiting) period ofapproximately 11 days. The system is pointable up to $45^{\circ}$ from vertical and covers $11 \mathrm{~km}$ $\mathrm{x} 11 \mathrm{~km}$ each swath.
In a manner similar to SPOT, the IKONOS 1-m panchromatic band can be used to sharpen colour bands. IKONOS bands and Landsat ETM+ bands are essentially identical in terms of spectral resolution (see Table 4). The IKONOs satellite, as true with many of the high-resolution systems, is highly maneuverable and can be programmed to point at a new target within seconds. Through the programming capability the whole system can follow a certain object, e.g. a river or a road.

After some initial problems, Quickbird was launched in June 2001. At that time, it was the second highest spatial resolution commercial imaging systemin the world and had the largest image size (see Table $\mathbf{4}$ for details). The panchromatic band, with a spatial resolution of $0.60 \mathrm{~m}$, is suitable for viewing city building structures. Similarly, the Orbview mission produced high resolution imagery and was active for 4 years, stoppingimageproductionin 2007. It had a revisiting time of 4 days and, similar to IKONOS, this satellite passes a given longitude at $10.30 \mathrm{am}$. The company GeoEye, owner of IKONOS and Orbview, launched GeoEye-1 in 2008 which carried the highest spatial resolution commercial sensor at that time. It provides $0.41 \mathrm{~m}$ in panchromatic mode and 1.65 in multispectral mode. After it's launch, Google Inc. disclosed to the public that they were going to buy and use GeoEye-1 imagery in their applications. Additional high resolution satellite sensors have since been launched, or are planned. A characterizationof satellite remote sensing systemsis found at www.satimagingcorp.com

The many available sensors with various spatial resolution and multi-temporal capabilities has called for research into the integration of data of the various types. There are many techniques available for the integration of remote sensing data and the general term used is "fusion techniques". Normally, the goal is to use the "fusion" images toderive more information than would be possible from the separate individual images [7]. A typical example is the fusion of SAR data with visible/infrared data. Another is the integration of the SPOT panchromatic high-resolution 
Table 2. Landsat Sensor Specification. Based on [5]

\begin{tabular}{|c|c|c|c|}
\hline \multirow[t]{2}{*}{ RBV } & 1,2 & $0.475-0.575$ & 80 \\
\hline & & $0.690-0.830$ & 80 \\
\hline \multirow[t]{4}{*}{ MSS } & $1-5$ & $0.5-0.6$ & $79 / 82^{\mathrm{a}}$ \\
\hline & & $0.6-0-7$ & $79 / 82^{a}$ \\
\hline & & $0.7-0-8$ & $79 / 82^{a}$ \\
\hline & & $0.8-1.1$ & $79 / 82^{\mathrm{a}}$ \\
\hline \multirow{6}{*}{$\mathrm{TM}$} & & $0.52-0.60$ & 30 \\
\hline & & $0.63-0.69$ & 30 \\
\hline & & $0.76-0.90$ & 30 \\
\hline & & $1.55-1.75$ & 30 \\
\hline & & $10.4-12.5$ & 120 \\
\hline & & $2.08-2.35$ & 30 \\
\hline $\mathrm{ETM}^{\mathrm{c}}$ & 6 & Above TM bands & $30(120 \mathrm{~m}$ thermal $)$ \\
\hline
\end{tabular}

$79 \mathrm{~m}$ for Landsat- 1 to -3 and $82 \mathrm{~m}$ for Landsat- 4 and -5 .

${ }^{\mathrm{b}}$ Failed shortly after lunch. ${ }^{\mathrm{C}}$ Landsat- 6 launch failure.

Table 3. SPOT-5 Sensors

\begin{tabular}{|c|c|c|c|}
\hline Sensor & Spectral Band $(\boldsymbol{\mu m})$ & Spatial Resolution $(\mathbf{m})$ & Swath Width $(\mathbf{k m})$ \\
\hline \hline HRG & Pan: $0.48-0.71$ & 2.5 or $5^{\mathrm{a}}$ & $60-80$ \\
\hline & $0.50-0.59$ & 10 & 10 \\
\hline HRS & $0.61-0.68$ & 10 & 120 \\
\hline Vegetation 2 & $0.78-0.89$ & $5-10^{\mathrm{b}}$ & 120 \\
\hline & $1.58-1.75$ & 1000 & 2250 \\
\hline & Pan: $0.49-0.69$ & 1000 & 1000 \\
\hline
\end{tabular}

${ }^{\mathrm{a}}$ The HRG panchromatic bands $(5 \mathrm{~m})$ can be combined to yield $2.5 \mathrm{~m}$.

${ }^{\mathrm{b}} \mathrm{HRS}$ panchromatic has a spatial resolution of $10 \mathrm{~m}$ along-track and $5 \mathrm{~m}$ in the across-track direction. 
Table 4. High-Resolution Satellite Systems

\begin{tabular}{|c|c|c|c|c|}
\hline Satellite & Launch Date & Spatial Resolution (m) & Spectral Bands $(\mu \mathrm{m})$ & Swath Width (km) \\
\hline \multirow[t]{3}{*}{ IKONOS } & Sept 24, 1999 & 1 & Pan: $0.45-0.90$ & 11 \\
\hline & & & $2: 0.52-0.60$ & \\
\hline & & & 3: $0.63-0.69$ & \\
\hline EROS-A & Dec 5, 2000 & 1.8 & Pan: $0.50-0.90$ & 13.5 \\
\hline \multirow[t]{3}{*}{ QuickBird } & Oct 18, 2001 & 0.61 & Pan: $0.45-0.90$ & 16.5 \\
\hline & & 2.40 & $1: 0.45-0.52$ & \\
\hline & & & $2: 0.52-0.60$ & \\
\hline \multirow[t]{5}{*}{ OrbView } & June 26, 2003 & 1 & Pan: $0.45-0.90$ & 8 \\
\hline & & 4 & 1: $0.45-0.52$ & \\
\hline & & & $2: 0.52-0.60$ & \\
\hline & & & $3: 0.63-0.70$ & \\
\hline & & & 4: $0.76-0.90$ & \\
\hline
\end{tabular}

channel with the SPOT multispectral low-resolution channel, which creates a sharpened color image [8].

The presence of lighting around the globe is almost entirely the result of human activities from settlements, shipping fleets, gas flaring or fires from swidden agriculture. Therefore, night-time light imagery serves as a unique human view of the Earth's surface. The Defense Meteorological Satellite Program-Optical Line Scanner (DMSP-OLS) was designed to observe clouds at night, but an unforeseen benefit was that it could also detect lights at night. The sensor is sensitive down to a minimum of $10^{-9} \mathrm{~W}$ $\mathrm{m}^{2} \mathrm{sr}^{-1} \mu \mathrm{m}^{-1}$ which is comparable to a light source similar to a unshielded $250 \mathrm{~W}$ high pressure sodium bulb light. A detailed review of DMSP-OLS is found in [9]. The nominal spatial resolution is $2.7 \mathrm{~km}$ but is frequently sampled to other spatial resolutions.

Research in technical issues and applications of DMSPOLS are ongoing and products are frequently being released. DMSP-OLS applications are presented in the section Applications of remote sensing to social science research. Three types of imagery are associated with DMSP-OLS data. The oldest data set is the stable lights data set, covering the period 1994-95. Through a filtering process, a variety of different image products can be derived: lights from human settlements and industrial facilities, fires, gas flaring and shipping fleets. The object's different temporal and spatial characteristics are used to discriminate between different types of light. The quality of the image products are, to some extent, dependent on the availability of cloud free views. This is problematic for the fire product as fires are more frequent in cloud-covered tropical regions. Perhaps the biggest problem with the first version was low-light level pixel saturation. The second version (1996-97), based on radiance-calibrated data, used a method to compensatefor the pixel saturation problem [10]. The use of radiance, as opposite to DNs (digital numbers) in the first version, provided a physically meaningful quantity and a versatile data set that could be used in modeling efforts and to find meaningful associations between radiance and other parameters. The most recent image product comes in the form of average DN values for 1992-93 and 2000 and is a change product based on the former two. Complications due to lunar illumination, glare, bad scan lines, and other minor problems are resolved in this version.

\subsection{Image Analysis}

Interpretation and analysis of remote sensing imagery involves the identification and measurement of various targets in an image in order to extract useful information about them. Targets in remote sensing images may be any feature or object which can be observed in the image. Image analysis can be done with visual interpretation and manual extraction of information. Observing the differences between targets and their backgrounds involves comparing different targets based on the visual elements of tone, shape, size, pattern, texture, shadow and association. Digital methods can be used to enhance the visual image analysis, so digital, manual, visual are not mutually exclusive concepts. For example, spectral bands can be combined to render a composite image that can help the analyst in the visual analysis process. True color composite images are created by combining spectral bands that most closely resemble the range of vision of the human eye. A Landsat ETM true-color composite uses the visible red (band 3), visible green (band 


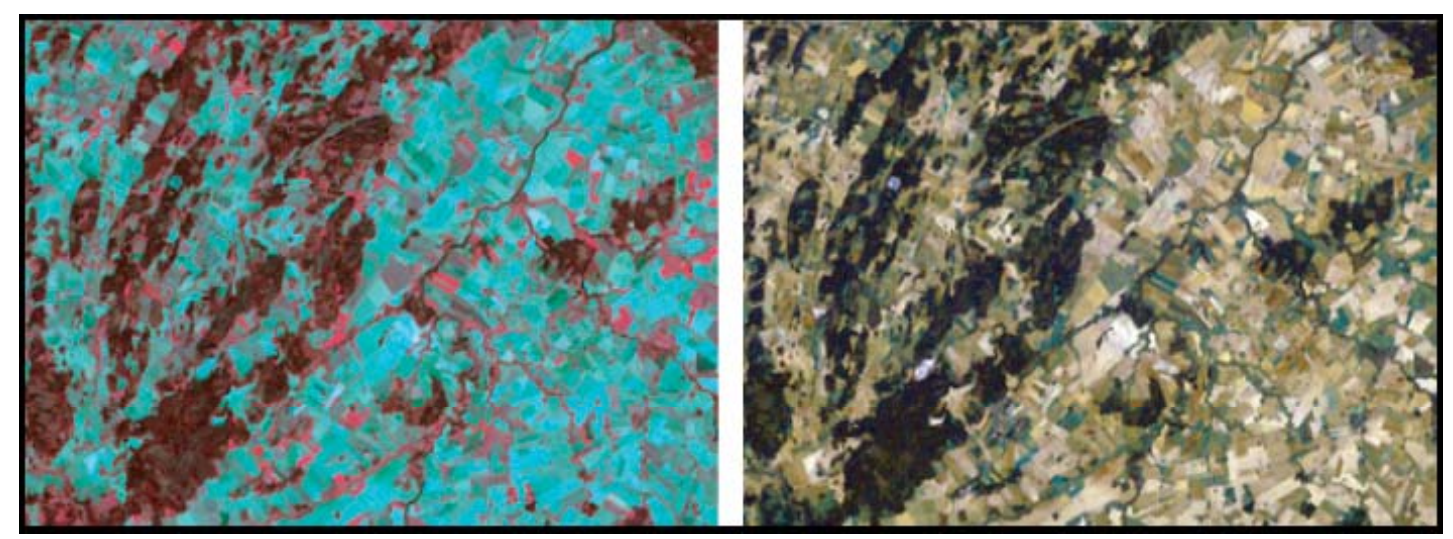

Fig. (2). RGB-composites from Landsat ETM+. Right: True-color composite from mapping band 3 to R, band 2 to G, and band 1 to B. Left: Near-infrared composite from mapping band 4 to R, band 3 to B, and band 2 to B. Scene acquired 2006-09-14. Coordinates for lower left corner are $\mathrm{N} 58^{\circ} 21^{\prime} 0^{\prime \prime}$, and $\mathrm{E} 12^{\circ} 52^{\prime} 54^{\prime \prime}$.

2), and visible blue (band 1) channels to create an image that is very close to what a person would expect to see in a photograph of the same scene (Fig. 2).

In a Near Infrared composite image, the visible blue band is replaced witha Near Infrared (NIR) band. The mapping of color to band is Landsat ETM Band $4(\mathrm{NIR})=$ red, Band 3 $($ Visible red $)=$ green, Band $2($ Visible green $)=$ blue Vegetation has a very high reflectivityin the NIR band because chlorophyll reflects energy at this wavelength. Thus, in a 432 NIR composite image, vegetation is vividly depicted as varying shades of red. Since different types of vegetation have different quantities of chlorophyll in their leaves, each type of plant has its own shade of red. This makes such composites very useful in determining the extent of vegetation and in classifying different vegetation types, as seen from space. Digital image classification uses the spectral information represented by the digital numbers in one or more spectral bands, and attempts to classify each individual pixel based on this spectral information. This type of classification is termed spectral pattern recognition and feature image types utilize different combinations of DNs, based on the inherent spectral reflectance and emission properties of the substance/feature in question. The objective of this imaging technique is to assign all pixels in the field to particular classes or themes (e.g. water, coniferous forest, deciduous forest, corn, wheat, etc.). The resulting classified image is comprised of a mosaic of pixels, each of which belong to a particular theme, and is essentially a thematic "map" of the original image.

Classification can also be based on spatial pattern recognition. This process involves categorization of image pixels on the basis of their spatial relationship to the pixels surrounding them. This type of classification tries to replicate the spatial synthesis process performed by the human brain during the visual interpretation process. Temporal pattern recognition uses time as an aid in feature identification. For example, distinct spectral and spatial changes during a growing season can permit discrimination in multi-temporal imagery.

When considering imageclasses, we need to distinguish between information classes and spectral classes. Information classes are those categories of interest that the analyst is actually trying to identify in the imagery, such as different kinds of crops, different forest types or tree species, different geologic units or rock types, etc. Spectral classes are groups of pixels that are uniform (or near-similar) with respect to their brightness values in the different spectral channels of the data. The objective is to match the spectral classes in the data to the information classes of interest. A large variety of software and methods exist for performing digital image classification and are divided into unsupervised and supervised methodologies. The former relies on a statistical grouping of pixels which have similar numerical information in the data (e.g. spectral classes),. These are then assigned to different information categories by the analyst. In supervised classification, the analyst takes the various information classes then identifies homogeneous representative samples for the different surface cover types (information classes) of interest. These samples are referred to as training areas. The numerical information in all the spectral bands of the pixels comprising these areas are subsequently used to "train" the computer to recognize spectrally similar areas for each information class. The above classifications are generally referred to as "per-pixel classification", as the pixel is the basic spatial and spectral unit.

Another class of digital image classification method has recently evolved in response to problems associated with the inability of per-pixel classification algorithms to handle high-resolution imagery, such as IKONOS or Quickbird data [11]. Such problems have created/resulted in a paradigm shift in remote sensing image analysis techniques [12]. Object-oriented image analysis is based on the paradigm that image-objects are the fundamental entity in remote sensing imagery. The term image-objects refers to individually resolvable entities located within a digital image that are perceptually generated from pixel groups [13]. From this, it follows that attributes such as shape, size and mutual relationships between objects can be used in the classification process. The initial stage involves segmentation of imagery based on some image-object characteristics (shape, variance, etc). The segmented object becomes the spatial unit used for spectral classification. Sometimes this 
process involves the aggregation of objects to coarser scales, e.g. tree objects are aggregated into forest.

\section{APPLICATIONS OF REMOTE SENSING TO SO- CIAL SCIENCE RESEARCH}

In the following sections applications of remote sensing to social science will be reviewed. A few words about the categorization is needed. The fields described below dominate the literature and resemble the categorization in previous reviews. Examples of remote sensing studies can probably be found in applications other than the ones described here. But those discussed below comprise the bulk of activity, are becoming important and thus debated. Some remote sensing applications are interrelated, both as a consequence of cross-disciplinary activities and the similarity in variables that are often desired and reused between disciplines. This is particular true for land cover, a category that is included in the majority of studies. We will describe remote sensing studies in the context of Urban studies, Demography, Archaeology, Land-use and landcover change studies, war and conflict studies. Finally, a section called "uncategorized" describes less common, yet nonetheless important, applications that don't fit traditional categorization.

\subsection{Urban Studies}

Remote sensing in urban studies has a long history. Early studies used photo interpreted data as auxiliary data sources in a census, or to predict socioeconomic variables such as poverty from housing density, structure type or vegetation cover [3]. Aerial photography remains in use today, but the need for frequent and comprehensive coverage of urban areas at low cost has led to an interest in satellite imagery. First generation low-resolution sensors permitted only limited analytical capability and were mainly used in regional systems analysis of some large North American cities. With the advent of Landsat TM and SPOT HRV it became possible to study European scale cities. Virtually all research in urban areas was focused on land use or land cover classification and it became evident that classification of urban land use and urban areas was a challenging task due to the mixture of materials requiring classification, but also because of ambiguous definitions ofwhat should be termed "urban". Technology oriented papers are numerous and only a limited number will be presented here.

Delineation and classification of urban areas have mainly been technical issues, each with their own value. Remote sensing experts are implementing new techniques, such as texture analysis and data fusion, to identify urban features, building types and building density [14]. The key issue is that the urban environment is characterized by a combination of materials and land use classes. Mixed pixels are common and limit the applicability of standard classification techniques. Consequently, during the period $1990-2000$, Rashed [15] applied multiple end-member spectral mixture analysis, landscape metrics and fuzzy logic to Landsat thematic images to study the urban morphology of Los Angeles, California. In a similar vein, Tole [16] applied a sub-pixel classification technique to remote sensing imagery between 1986 and 2001 to study changes in built-up and non-built-up areas. The problems with urban sub-pixel classification was also addressed by Xian [17], who studied the transition from natural cover to increasingly anthropogenic impervious surface in the Las Vegas area in Nevada.

To differentiate between single-family and multi-family residences, a minimum ground resolution of $1-5 \mathrm{~m}$ is required. For example, sensors like IKONOS and Quickbird are used to discriminate between duplex, triplex or condominium units. Researchers have also been experimenting with Airborne Laser Scanning (ALS) data to improve the classification of urban structures [18]. Additionally, land cover types were differentiated based on their relative height above ground, enabling the creation of a 3D building model. Hyperspectral data, acquired by means of MIVIS (Multispectral Infrared Visible Imaging Spectrometer),was also used for the purpose of detailed classification of urban elements and materials [19]. The analysis of the spectral responses for MIVIS, using more than 90 spectral bands, permitted the detailed classification of small variations in covering surfaces and the identification of a wide range of sub-classes (bricks, grits, copper, etc).

Measurement of physical properties such as surface temperature, pollutants or water vapor has mainly been the realm of technical remote sensing. Remote sensing has contributed significantly to studies of the heat island effect, i.e. the observed temperature difference between urban and rural areas. Santana [20] studied the normalized difference vegetation index (NDVI), Leaf Water Content index (LWC) and land surface temperature to aid in city landscape design. They suggest that theses indices can be used for selecting areas with the greatest need for green area development. In another study, Jusuf et al. [21] identified land use types that had the greatest influence on ambient temperature increasein Singapore.

Other social science issues applicable to remote sensing exist, such as are urban growth and development, quality of life, and urban population density and structure. Several studies exist that quantify land cover changes in order to address urban growth over periods of time. However, this application is particularly demanding in terms of preprocessing of remote sensing data. It is required that different temporal images are corrected for differences in atmospheric conditions, sun angle, and are carefully coregistered to avoid errors in the estimation of the land cover change. In an attempt to understand the extent of, and the factors driving urban expansion in China from the late 1980s to 2000, Deng [22] combined socioeconomic variables and high-resolution satellite imagery. Rawashdeh and Saleh [23] investigated the effects of urbanization on fertile lands and also quantified urban growth through the study of aerial photographs, Landsat and IKONOS data for the period 19182002. They showed that urban areas increased 509-fold and fertile land loss was 23\%. Wilson and Lindsey [24] investigated the potential driving forces and environmental impacts of urban and suburban development of rural lands in the state of Indiana, US. Land cover change derived from Landsat data was related to socioeconomic variables and the findings indicated that residents in areas experiencinghigher levels of growth were less efficient consumers of rural land.

Martinuzzi et al. [25] studied land development and urban sprawl in densely populated Puerto Rico. They combined census data and remote sensing data in a 
comprehensive land classification scheme. Ackerman et al. [26] used satellite remote sensing in combination of morphometric analysis to study the urban dynamics in the Petite Côte region of Senegal.

Environmental quality and quality of life are concepts that are sometimes used interchangeably. The first concept is closely related to the quality of the environment surrounding a human population. The latter concept usually involves some variables of socioeconomic quality such as affluence, housing quality, etc. Nichol et al. [27] investigated the application of multispectral remote sensing from Landsat ETM+ and IKONOS satellite sensor for the mapping of urban environmental quality in Hong Kong. More specifically they studied the relationship between air quality, biomass and surface temperature. In a similar study, they analyzed the same problem but also investigated the fusion between Landsat thermal data and IKONOS [28]. For visualization purposes, they developed a 3D urban model with fly-through capabilities. Jensen et al. [29] used remote sensing data and regression analysis to study the relationship between socioeconomic variables and urban forest amenities in Terre Haute, Indiana. They showed a linkage between income, population density and forest amenities measured as leaf-area. Lo and Faber [30] used the NDVI developed from Landsat TM data together with 1990 census data to measure quality of life of the Athens-Clarke county in Georgia. They showed that greenness was positively correlated with income and median home value, and negatively correlated with population density. In contrast, research performed in Detroit found that increase in greenness levels is positively correlated with indicators of social decay [31]. This seemed to be related to population decay and abandonment of housing units. Pozzi and Small [32] compared vegetation patterns and population density for a number of suburban areas in the U.S. and found that this relationship varieswidely. Increase in greennesscould relate to both high and low levels of affluence.

One obvious application of night-time lights is in the mapping of urban extent. DMSP-OLS imagery has a tendency to overestimate urban areas as a consequence of overglow, but also underestimate where no electricity is present. Imhoff [33] investigated different thresholding techniques to compensate for the overglow problem and through comparison of their data with those of the US census bureauthey found no differences between the two areal assessments. Sutton et al. [34] used a radiance-calibrated data set to study urban sprawl in the US. A data set of impervious areas has been produced by NOAA-NGDC (National Oceanic \& Atmospheric Administration - National Geophysical Data Center) and night-time lighting was also used to delineate urban areas for the Global Rural-Urban Mapping Project (GRUMP) data set.

DMSP-OLS has also been used to map global urban extent [35], but also global estimates of market and nonmarket values derived from nighttime satellite imagery, land cover, and ecosystem service valuation [36]. Results from these studies suggest that the relationship between lit area and population density varies considerably among small cities and towns and is more consistent for large urban areas. The precision of population estimates from the DMSP-OLS sensor has been evaluated and the conclusion is that it varies significantly on a regional basis. Studies in the USA indicate that towns with 150 inhabitants can be detected but recent work reports that for Brazilian Amazon urban settlements only populations higher than 5000 were precisely identified [37, 38]. Lu et al. [39] showed that DMSP-OLS data, when combined with MODIS (Moderate Resolution Imaging Spectroradiometer) NDVI data, greatly improved assessments of spatial patterns of settlement distribution.

\subsection{Demography}

Population distribution surveillance is by tradition done by demographers but recently contributions from the spatial sciences have been noted. Spatial population distributions may reflect either residential or ambient population. Residential population information is derived from data describing where individuals reside. This type of data is usually aggregated to administrative or political boundaries. Ambient population descriptions capturethe exact locations of individuals, rather than where they reside and is usually represented by a grid. In data-poor countries, ambient population can be inferred with the help of remotely sensed data [40].

\subsubsection{Population Counts}

Several attempts exist where remote sensing imagery was used to produce population counts. Stern tested the correlation between village size and population size in a study aimed, originally, at improvingdata comparing population size withdesertification processes in the Kordofan Province in the Sudan [41]. Villages were identified with Landsat MSS imagery and compared with the number of inhabitants. Due to deficiencies in reliable ground-thruth, the high correlation between settlement size and population size could not be statistically verified. In Nigeria, Olurunfemi [42] worked in a similar vein and found that 92 percent of the variation in population density could be explained by housing as a category of land use, detected in aerial photographs. He used a mathematical model to assign population counts to the land use data. This type of methodology prevails in the field of spatial demography.

Jensen and Cowen [43] summarize this line of research by stating that population estimates can be derived from counts of dwelling units, measures of urban extent and landuse/land-cover classification. From an image classification point of view, several criteria need to be met, e.g. identification of housing structures through tree cover and differentiation between residential, commercial and industrial structures. For the independent variable average number of residents per dwelling unit estimates are necessary. This quantity can also be used to estimatenonresidential populations (homeless, seasonal workers, etc.). Similarly, Li and Weng [44] used Landsat ETM+ imagery together with census data to estimate population densities for the city of Indianapolis, Indiana. Liu et al. [45] explored the relation between census population data and high spatial resolution IKONOS satellite imagery. They compared different types of measurements of texture to population census data but found only weak correlations. de Sherbinin et al. [3] concluded that research in this field is usually not performed by demographers and not much work has been evaluated by demographers. To be successful, detailed 
observations and local knowledge are needed, an approach which usually is expensive, at least for large areas.

It seems clear that not even high-resolution satellite imagery of built-up areas correlates sufficiently strongly with population data to serve as a proxy for population [45]. However, demographers acknowledge that remote sensing imagery is a valuable aid in the initial selection of sampling units for traditional census work. Furthermore, the margin of error in population counts is too wide for remote sensing to be a viable alternative to traditional techniques [46].

\subsubsection{Population Allocation}

Census data can be combined with remote sensing information to generate a spatial distribution of population. Distributions may demonstrate residential or ambient populations. In essence, this is disaggregation of data based on spatial attributes rather than sub-districts. Allocation of populations is performed through spatial interpolation based on one or more geometric attributes. These geometric attributes can be derived from remote sensing imagery and are typically land-use, roads, night-time lights or some other feature related to human presence.

Output from population allocations is, in most cases, presented as a grid with population counts assigned to each cell with a resolution of around, typically,1-10 km. Some are distributed free of charge such as LandScan [47], Gridded Rural-Urban Mapping Project (GRUMP) [48] and Gridded Population of the World (GPW) [49]. For example, Hall et al. [50] used the above data sets with addition of a proxy for world poverty, environmental vulnerability, and distribution of natural hazards in a small-scale map to pin-point areas with high population densities, high levels of poverty and a pronouncedrisk for natural hazards.

Population predictions from remote sensing and nighttime light data relies on empirical observations of the relationship between the geographical size of a settlement and its population. In the 1960s Tobler [51] established that human population could be estimated by measuring the size of human settlements. Photographs generated from the Gemini space flight program were used in the characterization of settlements and empirical relations were developed for estimating populations. The coefficients for these relations showed regional variation, which was explained by differences in the organization of spatial activity and socioeconomic settings. Sutton et al. [52] found a correlation between night-time lights and human population density for the continental USA. Area of light at night has also been observed to correlate with population figures, regardless of economic development [53, 54]. Doll [55] extended this to analyze the relationship betweenarea of illumination area and urban population in different countries.

Night-time lights seem to be more indicative of day-time populations, since there is a large daily migration of people from residential areas to places of work. This concept has been used in the construction of a global database of ambient population from DMSP-OLS light and other spatial data. The Landscan database was developed at Oak Ridge National Laboratory and describes population at a global scale at 30 arc-minute $(1 \mathrm{~km})$ resolution [47]. The underlying census model counts at the sub-national level and incorporates four spatial input datasets, namely land cover, roads, slope and night-time lights. The model allows for differences in regional settlement characteristics. Night-time lighting was also used in the construction of the GRUMP dataset, to allocate populations from large census units into urban areas [49].

Several studies exist where the primary research focus is related more closely to population dynamics, rather than estimation of population. In these studies, population is viewed as the independent variable, the opposite of the above examples where population is considered a dependent variable. Entwistle et al. [56] studied the relationship between household survey data and landscape pattern derived from remote sensing imagery. They showed that a fragmented landscape with small patches promoted outmigration of young farmers. Qiu et al. [57] compared urban population growth modeling based on change detection information from remotely sensed data and TIGER (Topologically Integrated Geographic Encoding and Referencing system, from the U.S. census bureau) GIS road data.The latter showed slightly greater accuracy.

\subsection{Archaeology}

Nearly a century ago, archaeologists started utilizing photographs taken from airplanes to gain an aerial view of sitesandidentifythe remains of ancient settlements [58]. From the air, researchers could study crop marks, vegetation patterns and composition as evidence of past human activity. Additionally, larger and more remote areas could, for the first time, be surveyed. During the first era of satellite remote sensing (1960-80), the majority of archaeologists were restricted to using aerial photographs and visual interpretation of imagery, due to botha lack of technical aids and the low spatial resolution of these early sensors. During this period, prehistoric roadway systems in the Chaco Canyon of New Mexico were discovered in the pioneering remote sensing study of Lyon and Avery [59].This early work was summarized in a handbook of remote sensing techniques for archaeologists [59, 60]. In 1984, NASA organized the first conference on remote sensing in archaeology to discuss recent NASA-led advances in the technology and future applications to archaeology [61]. In the mid 1990s undergraduate and graduate courses were developed at the newly started Center for Remote Sensing at Boston University [62]. Strikingly, archaeology researchers were quick to embrace, and adapt to their needs, the full range of the remote sensing technology available to them. Sever [63] used thermal scanners to extend the work in the Chaco Canyon project. Synthetic Aperture Radar (SAR) and Light Detection and Ranging (LIDAR) techniques were tested and found useful for detecting road networks and pathways [64]. These investigations had a fundamental impact on the research community. Subsequent excavation workat prehistoric sites validated the initial SAR and LIDAR discoveries [64]. In many areas, such prehistoric footprints may have otherwise escaped detection,due to dense vegetation cover, sand, or similar.

The most recent development in the application of remote sensing in archaeology is the use of radar imagery [61]. Radar transmissions have the ability to penetrate certain objects and are therefore useful where surface features are covered by dense vegetation and can, to a certain 
extent, detect sub-surface features. SAR was used to detect ancient water courses, roads, forts and settlements once established along the Silk Road but now largely covered with sand [63]. Recently, it was discovered that the medieval settlement of Angkor in Cambodia was part of a much larger complex of low density settlement landscape,which possessed an elaborate water management network, making it the most extensive urban complex of the preindustrial world [65]. In this project, traditional field survey methods were used in combination with radar remote sensing data collected during the 1994 flight of the space shuttle Endeavour. This enabled penetration of the forested areas on the Angkor site in the vicinity of the great temples.

Aerial photography has a solid foundation in archaeological research and surveying. The advent of satellite imagery provided researchers with increased overview to the cost of spatial resolution. Early sensors with low resolution, such as Landsat MSS $(80 \mathrm{~m})$ had only limited value in archaeology. But as the spatial resolution of satellite remote sensing has increased, so has the degree of interest and usage by archaeologists. IKONOS $(1 \mathrm{~m}$ panchromatic, $4 \mathrm{~m}$ multispectral) launched in 1999 followed by Quickbird ( $0.61 \mathrm{~m}$ panchromatic, $2.40 \mathrm{~m}$ multispectral) in 2001 has narrowed the gap between aerial photographs and satellite imagery in terms of high spatial resolution. However, the benefit high-resolution satellite imagery offers over traditional aerial photographs is that images can now be processed with the full set of remote sensing techniques in a digital environment. Saturno et al. [66] used IKONOS, Quickbird and EO-1 to detect ancient settlements in Guatemala, which have long been covered by dense vegetation. They studied the variations in vegetation density and structure caused byhuman activities. Garrison et al. [67] used IKONOS imagery to study sites where the Maya once lived and discussed the dangers and pitfalls of implementing remote sensing methods developed for similar but not identical landscapes. They identified differences in climate, geology, hydrology and topography as variables that affect the analysis. Bitelli and Zanni [68] have discussed the problem of the georeferencing of high-resolution satellite imagery and integration with other datasets. Masini and Lasaponara [69] used Quickbird imagery and edge detection techniques to detect land division systems in Metaponto, Italy. These critical views towards remote sensing data and techniques are quite typical in archaeology.

Archaeologist embrace new data and techniques quite rapidly. Recently, they started using LIDAR (Laser Imaging Detection and Ranging) techniques, which have proven useful in detecting archaeological sites covered by vegetation and surface disturbances [70]. Several other sensors are used in archaeological research, for example, ASTER and SPOT. ASTER has gained some popularitydue to it's low cost. Also, old sensor data acquisition systems are finding new applications. For example, the military spy satellite CORONA, and on-board imagery system was released to the public in the mid-1990s. CORONA was used to take photographs of the Earth's surface during intelligence missionsbetween 1960-72 [71, 72]. It was originally designed to identify enemy vehicles but presently has research applicationsin many fields.

\subsection{Land-Use and Land-Cover Change}

The interpretation of land-use and land cover change data dominates the research agendas of many private and public research institutions [3]. An understanding of land-change has emerged as a fundamental element of how global environment change is occurring and the sustainability sciences have called for an integration of the social and physical sciences. Human land use is a critical link between society and the modification of hydrology, ecology, geomorphology, climate and biogeochemical processes. Land use is the term that describes the human use of the land, e.g. grazing and agriculture. Land cover refers to the physical and biological cover types that characterize an area, e.g. forest, tundra or grassland. Over the past decades there have been several major international research efforts to link the social and natural sciences through the study of land-use and land-cover change (e.g. IGBP (International GeopshereBiosphere Programme)-IHDP (International Human Dimension Programme), LUCC (Land-Use and Land Cover Change), ESSP Earth System Science Partnership). Linking socioeconomic data with remote sensing data was central in all these projects. Liverman and Cuesta [73] concluded that progress has been limited because of difficulties in gathering socio-economic information at both global and regional scales, linking social data to satellite imagery, and forecasting human activities and policies. Numerous studies exist that merely quantify and observe land cover changes without providing any explanations. Those studies are omitted from this study.

Satellite remote sensing provides great opportunities in the measurement of worldwide land-cover change, particularly so because of the continuous improvements in the spatiotemporal resolution of the data and because the range of monitoring variables is increasing. This is important because social scientists currently lack comprehensive and regularly updated data on socioeconomic activities across the world. International organizations advise governments to conduct surveys or to collect new demographic, economic and agricultural data at least every 10 years, but the resulting data sets are invariably fraught with errors, gaps and inconsistencies [73]. The alternative to collecting census data is to conduct household surveys to collect relevant variables at an appropriate level of precision. The cost of such fieldwork often means that large areas cannot be covered and cross-sectional studies are often used as weak substitutes [74].

Social scientists use a variety of approaches to explain the causes of land-cover and land-use change, and use a plethora of methods and data. Theories from many different disciplines, including anthropology, economics, demography, and geography, contribute to divergent social theories of environmental change and alternative explanatory variables.

Reining [75] and Conant [76, 77] where among the first in the field of anthropology to link ethnographic data obtained from local populations to their Landsat-based study of subsistence systems. Anthropology, in general, represents one end of the scale spectrum, as the independent variables used are usually obtained at the level of individuals or households. Anthropologists provide important insights into land use practices (and environmental change) from their 
understanding of cultural and social conventions, but their contributions are inevitably found ata level of detail that, not until recently, could be matched with satellite data. Therefore, those disciplines conducting sub-community research have for long relayed on field work in combination with aerial photographs. The attraction of using remote sensing data to generalize over large geographical areas has led socialscientists to, sometimes, over-interpret and extrapolate their data. For example, Turner [78] argued that earlier claims of desert expansion in the Sahel region of Africa, was based on regionalized generalizations of highly localized observations. Bad weather conditions and high costs for field work have led researchers to generalize from field observations at one locality and time to broader regions over longer times. In addition, the increased use of remotely sensed data has worked to address the problems of spatial and temporal bias and inappropriate generalizations.

Among the earliest social science applications of remote sensing were those combining land-use and land-cover (LUCC) data with socioeconomic data to isolate those socioeconomic drivers responsible for landscape change. Deforestation has received the greatest amount of research attention. De Sherbinin et al. [3] suggest that time series remote sensing imagery has been particularly valuable in this kind of research because the conversion of forested land to that useful for other applications is easy to detect. In contrast, the conversion of land from residential to commercial use, or from cropland to pasture, is more difficult to detect and requires the labour-intensive collection of high resolution data. The most common and widespread approach instudying such land use changes is to monitor the amounts and rates of forest cover change between two periods in time. A number of studies have related land-cover information derived from satellite data to agroeconomic and socioeconomic data in order to test hypotheses about how population (growth), agricultural production and other factors contribute to land-cover change [73]. Geist and Lambin [79] found that, in the case of deforestation, agricultural expansion followed by infrastructural development was the most significant cause, and that economics and institutional factors were more important than demographic variables, such as population growth.

Temporal and spatial inconsistencies between remote sensing data and socioeconomic data are usually resolved by aggregating pixel information to the units of the socioeconomic data (administrative units, census tracts etc). Wood and Skole [80] aggregated forest cover change data to the administrative census units in the Brazilian Amazon in orderto identify and rank socioeconomic and demographic variables associated with forest clearings. Similarly, Pfaff [81] combined aggregated forest cover from remote sensing data with both population and economic variables. The comparison of their results showed that population density did not have a significant effect on deforestation rates. In contrast, Wood and Skole showed that conflicts between land holders and ranchers and the number of rural migrants had a significant effect on deforestation, while Pfafffound that vegetation density and soil quality and factors affecting transportation costs were of greatest contributing factors.

Adissatisfaction with aggregate remote sensing data has spurred researchers to work with high-resolution socioeconomic data. Significant effort has been invested in farm property and household level surveys which are then linked to remote sensing imagery at the same or a higher level. GPS (Global Positioning System) has been used for the co-registration of survey data and satellite data. Dessie and Kinlund [82] investigated the relationship between the cultivation of the stimulant drug Khat and forest decline in the Wondo Genet area of Ethiopia. They combined Landsat TM data with social survey techniques. They found that Khat production impacted forest cover through proximate causes, such as increased activities near forests, new settlement patterns, suppression of other crops, and increased demand for wood.

Some studies relate spatial patterns produced by different land management regimes. Lorena and Lambin [83, 84] investigated the spatial patterns associated with deforestation in the Brazilian Amazon and tested the old hypothesis that a particular pattern was related to a particular variety of socioeconomic process. In this type of research spatial statistics are usually employed to characterize and quantify the observed pattern. Software developed for ecology applications, e.g. Fragstats [85], can be used in combination with remote sensing data. However, spatial indices are scaledependent and results may change if the scale is changed [86].

Fewer studies exist that link socioeconomic data with remote sensing data for conversions other than deforestation. Xie et al. [87] examined the impact of the farmland protection policy institutionalized for China's paddy field conversion in the mid-1990s. They used remote sensing to obtain measures of paddy field changes and applied multiple regression analysis to explore the interactions between paddy field change and socioeconomic factors. McCracken et al. [88] overlaid property boundaries on multi-temporal Landsat data and traced property level land-cover patterns to differences in livelihood strategies of households. In a similar vein, Hall and Jansson [89] combined satellite data with property boundaries derived from historical maps from the 1850's for a rural area in central Sweden. They found a relationship between historical land-use, settlement patterns and modern land-cover. Long et al. [90] studied the spatiotemporal patterns derived from Landsat TM (1990-2006) in combination with socio-economic data for coastal China. They showed that, population growth, rapid industrialization and urbanization were the major driving forces of farmland change, and China's economic reforms have played an important role in the transformation of rural settlements.

Remote sensing technology is evolving at a pace that exceeds the ability of national, institutional, or research efforts to collect socioeconomic data at a relevant level of detail. Property boundaries and patterns of land ownership arethe keys to understanding landscape transformation, but are nevertheless often a missing ingredient in remote sensing data. Nevertheless, this type of social data is relatively easy to merge with remote sensing data, thereby greatly enhancing overall data quality. Landscape change studies are difficult. Some social scientists, who have solid training in field work and aerial photograph interpretation, have high hopes for satellite data. 


\subsection{War and Conflict Studies}

Academic research, using remote sensing, on war and conflict and their aftermath is very limited [91]. Satellite surveillance has, since the 1960's, been essential in warfare activities because it provides information on enemy missiles, troop deployments and military positioning. CORONA was probably the first satellite deployed for this purpose, in 1959. Imagery from CORONA was made public in 1995. In conflict studies, satellite imagery is used for observing the immediate impacts of military action. The Gulf crisis in 1990-1991 demonstrated that systems imaging from space could play a major role in strengthening conventional capabilities. American reconnaissance monitored, for example, Iraqi troop deployments, thus obtainingan early warning of the possible launch of Iraqi missiles. Remote sensing has also played a role in monitoring nuclear weapons testing. Jasani [92] developed a test based on Landsat data which decides whether nuclear tests areimminent. Criteria include: construction of roads, tunnels and land disturbances, as well as changes in the Earth surface structure due to detonations. Some attention has been directed towards land cover changes caused by military action. Remotely sensed data was used to study vegetation regeneration of mined agricultural areas and service roads along minefields in Zimbabwe [93]. In another example, with Landsat MSS data, it was possible to map and quantify a $50 \%$ reduction in agricultural productivity due to the Sandinista insurgency in Nicaragua. Isolated areas of abandoned land were visible until 1996, as observed from Landsat, SPOT and NOAAAVHRR imagery [94, 95].

Landmines can remain active for long time after conflicts have formally ended. Detecting and removing landmines is hazardous and tedious work. Recent research into landmine detection with remote sensing data shows good results. Historically, different types of radar detection were used but recent trends involve fusion of, for example, radar data with hyperspectral data [96]. Zare et al. [97] used long-wave hyperspectral data in combination with SAR data. They showed that vegetation mapping in combination with mine detection algorithms could minimize false alarms due to vegetation forms (round bushes), otherwise mistaken for mines.

\subsection{Uncategorized Applications}

During the course of this study several interesting projects were discovered that didn't conform to the categorization used here. Quantitatively, these studies are too few to be formally recognized as new and separate categories, but they deserve to be mentioned anyway.

The relationship between night-time lights and economic activity was first described by Elvidge et al. [54]. Doll [37] extended these observationsby using satellite data in a study comparing illuminated area with GDP and created the first map,with a resolution of $1^{\circ} \times 1^{\circ}$, of disaggregated GDP. Night-time lights and per-capita GDP lights have also been associated to the targeting of health resources [98].

Green house gas emission mapping has also been an area where night-time lights are expected to contribute. Elvidge et al. [54] were first to identify the correlation between lit area and gas emissions. Doll et al. [37] created and compared a map of carbon dioxide levels from the Carbon Dioxide Information Analysis Center (CDIAC) with a map of nighttime lights and noted that, for the observed relationship, night-time lights were a poor estimate of direct emissions, but performed better in mapping the spatial distribution of emissions. Toenges-Schuller [99] extended gas emission mapping to include $\mathrm{NO}_{\mathrm{x}}$ (generally attributed to motor vehicle usage, power generation and industry). Cinzano [100] used the radiance-calibrated night-time lights data set to defineunlit areas polluted by proximal light sources. Many areas that should appear dark in the night-time light data set, due to absence of ground level light sources, are in fact affected by light from adjacent bright areas. By comparing and combination these data with the Landscan population database, the number of people affected by light pollution was calculated to be $99 \%$ in the developed world and $66 \%$ globally. Walluda et al. [101] used night-time imagery to target the size of fishing fleets harvesting the jumbo squid in the Eastern Pacific. Fishing fleets can be detected because they use powerful lamps to attract fish.

The presence or absence of light also has the potential to be used in disaster management and wildfire surveillance. Kohiyama et al. [102, 103] described how DMSP-OLS data can be used in a disaster information system to provide early estimates, in near-real time, of how areas become damaged. Finally, De Souza-Filho [104] used DMSP-OLS to monitor the Brazil energy crisis in 2001. They found a link betweenan energy dip in electrical output in 2001 with changes in illumination levels from the previous year.

\section{CONCLUSION}

The overall impression, from a review of the literature on remote sensing in the social sciences, is that the use of such technology is widespread but can, in many researchareas, be considered immature. The technology has been refined to a sophisticated level in, for example, some areas of urban study, were data fusion and advanced modeling has been successfully combined with remote sensing data. In other fields, as demonstrated by what has been published in related journals, researchers have failed to adhere to typical conventionsin remote sensing, such as accuracy assessments of classification results.

Surprisingly, some of the issues identified in some of the pioneering work, e.g. linking remote sensing data (pixels) with socioeconomic data (aggregate, administrative units), have not been addressed. In addition, the imbalance between technological developments and the increase in remote sensing data availability has sometimes, in many regions of the world where socioeconomic data is scarce, led to data simplification and trivialization issues. For example, Longley [105] remain doubtful as to whether urban remote sensing and GIS have had contributed positively to the body of knowledge of urban geography. The technical challenges relating to the study of urban environmentsare at risk of absorbin gurban remote sensing methodologies too quickly, to the detriment of improving the theoretical foundations needed for accurate data interpretation.

Many of the variables of interest in contemporary social science research are not directly observerable from space. Societal artifacts, such as roads, buildings, farmland etc. are less relevant than those abstract variables and processes that 
are the driving forces behind the creation of the observable physical objects. Land-use changes and changes in building patterns are more likely an expression of changes in legislation, traditions, and social and economic conditions. There is a substantial risk that remote sensing based social science will become a second class of social science.

Not surprisingly, remote sensing is firmly based in those disciplines that are dependent of identification of surface (or sub-surface) based objects, e.g. as in archaeology. Remote sensing techniques are often used by archaeologists in a first explorative stage, and are then substituted with traditional methods. Variables are not extracted from remote sensing imagery and correlated with socioeconomic variables, meaning that archaeology avoids the critique of being datadriven. Also, a sign clearly demonstrating the acceptance of remote sensing technology into this discipline is that the number of publications specifically investigating the value and application of remote sensing technology and techniques is decreasing. This evolution can be noted for archaeology but not yet for urban studies, where articles addressing technical issues and methodologies dominate the literature. In archaeology, a critical debates regarding methods are ongoing and is interpreted as a readiness within the discipline to embrace new technology and data sources.

Remote sensing and remotely sensed data do have a place in the social sciences and is at its most valuable in this arena when it is used in combination with traditional methods, such as surveys, public records, interviews and direct observation, or when there is a need for data describing rapidly evolving processes. A typical example of the latter is in the rapidly-developing countries of southeast Asia, where the scale and magnitude of urban development is without historical precedent. Remote sensing data must be viewed with the same scrutiny as other sources. There is a tendency to overemphasize the role of remote sensing data in some studies and a regression towards simplified perspectives on process and form relations can be noted. When combined with other sources, e.g. maps, tabular data, remote sensing data can be a powerful source of information. In that context I would like point to the study of Khat production [82] where remote sensed data is used in a most traditional manner but with good results. Forest decline was measuredusing remote sensing techniques, whilst simultaneously interviewing the local inhabitants.

The spatial resolution of present day sensors are close to aerial photography $(<1 \mathrm{~m})$, satellite data archives cover almost 40 years of observations, and remote sensing data is being produced with an never ending increase in spatial and temporal resolution. Social scientists can choose how to process remote sensing data: visually, manually, automatically, statistically or they can order pre-processed information products for direct use in some GIS software. Compared to the situation 15-20 years ago, is quite different when visual quality was lower and the need for in-house remote sensing expertise much more important. The challenge today is not in technical issues but more in the indepth understanding that remote sensing imagery as an information source has flaws and limitations, just as other sources do.

\section{ACKNOWLEDGEMENT}

This work was conducted within the Mapping the Politics of Ecology (MAPLE) project funded by the Foundation for Strategic Environmental Research (MISTRA). We gratefully acknowledge the constructive comments from the reviewers that significantly improved the paper.

\section{REFERENCES}

[1] Morain SA. A brief history on remote sensing applications, with emphasiz on Landsat. In: Liverman D, Eds. People and pixels: linking remote sensing and social science. National Academy Press, Washington, 1998; pp. 28-50.

[2] Liverman D. People and pixels: linking remote sensing and social science. National academy press: Washington, 1998.

[3] de Sherbinin AD, Balk D, Yager K, Jaiteh M, Pozzi F, Giri C. Social science applications of remote sensing: a ciesin thematic guide. Center for international Earth science information network of Columbia network. 25 March 2010. Available from: http: //sedac.ciesin.columbia.edu/tg/guide_main.asp.

[4] Aronoff S. Remote sensing for GIS managers. ESRI Press; Redlands, 2005.

[5] Lillesand T, Kiefer R, Chipman J. Remote sensing and image interpretation: John Wiley \& Sons; New York, 1994.

[6] Harrie L. Geografisk informationsbehandling: teori, metoder och tillämpningar. Stockholm, 2008.

[7] Pohl C, van Genderen JL. Multisensor image fusion in remote sensing: concepts, methods and applications. Int J Rem Sens1998; 19: $823-54$

[8] Cliche G, Bonn F, Teillet P. Integration of the SPOT panchromatic channel into its multispectral mode for image sharpness enhancement. Phot Eng Rem Sens 1985; 51: 311-6.

[9] Doll CNH. CIESIN thematic guide to night-time light remote sensing and its applications. Center for international earth science information network of Columbia university. 25 March 2010. Available from: http: //sedac. ciesin. columbia. edu/tg.

[10] Elvidge CD, Baugh KE, Dietz JB, et al. Radiance calibration of DMSP-OLS low-light imaging data of human settlements. Rem Sens Env 1999; 68: 77-88.

[11] Hay GJ, Marceau DJ, Dube P, Bouchard A. A multiscale framework for landscape analysis: Object-specific analysis and upscaling. Land Ecol 2001; 16: 471-90.

[12] Hall O, Hay GJ, Bouchard A, Marceau DJ. Detecting dominant landscape objects through multiple scales: An integration of objectspecific methods and watershed segmentation. Land Ecol 2004; 19: 59-76.

[13] Hay GJ, Niemann KO, Goodenough DG. Spatial thresholds, imageobjects, and upscaling: A multiscale evaluation. Rem Sens Env. 1997; 62: 1-19.

[14] Wentz EA, Nelson D, Rahman A, Stefanov WL, Sen Roy S. Expert system classification of urban land use/cover for Delhi, India. Int J Rem Sens 2008; 29: 4405-27.

[15] Rashed T. Remote sensing of within-class change in urban neighborhood structures. Comp Env Urb Syst 2008; 32: 343-54.

[16] Tole L. Changes in the built vs. non-built environment in a rapidly urbanizing region: A case study of the Greater Toronto Area. Comp Env Urb Syst 2008; 32: 355-64.

[17] Xian G, Crane M, McMahon C. Quantifying multi-temporal urban development characteristics in Las Vegas from landsat and ASTER data. Phot Eng Rem Sens 2008; 74: 473-81.

[18] Aubrecht C, Steinnocher K, Hollaus M, Wagner W. Integrating Earth observation and GIScience for high resolution spatial and functional modeling of urban land use. Comp Env Urb Syst 2009; 33: 15-25.

[19] Fiumi L. Evaluation of remote sensing data for urban planning Applicative examples on some Italian towns remotely sensed by means of MIVIS sensor. Proceedings of XXX Iahs World Congress on Housing; 2002: 1045-50.

[20] Santana LM. Landsat ETM+ image applications to extract information for environmental planning in a Colombian city. Int $\mathbf{J}$ Rem Sens 2007; 28: 4225-42.

[21] Jusuf SK, Wong NH, Hagen E, Anggoro R, Hong Y. The influence of land use on the urban heat island in Singapore. Hab Int 2007; 31: $232-42$. 
[22] Deng XZ, Huang JK, Rozelle S, Uchida E. Growth, population and industrialization, and urban land expansion of China. J Urb Econ 2008; 63: 96-115.

[23] Al Rawashdeh S, Saleh B. Satellite monitoring of urban spatial growth in the Amman area, Jordan. J Urb Plan Dev 2006; 132: 211 6.

[24] Wilson JS, Lindsey GH. Socioeconomic correlates and environmental impacts of urban development in a central Indiana landscape. J Urb Plan Dev 2005; 131: 159-69.

[25] Martinuzzi S, Gould WA, Gonzalez OMR. Land development, land use, and urban sprawl in Puerto Rico integrating remote sensing and population census data. Land Urb Plan 2007; 79: 288-97.

[26] Ackerman G, Mering C, Quensiere J. Analysis of built-up areas extension on the Petite Cote region (Senegal) by remote sensing. Cybergeo, Cartographie, Imagerie [249]. 25 March 2010: Available from: http: //www.cybergeo.eu/index3884.html

[27] Nichol J, Wong MS. Modeling urban environmental quality in a tropical city. Land Urb Plan 2005; 73: 49-58.

[28] Nichol J, Wong MS, Fung C, Leung KKM. Assessment of urban environmental quality in a subtropical city using multispectral satellite images. Env Plan B Plan Des 2006; 33: 39-58.

[29] Jensen R, Gatrell J, Boulton J, Harper B. Using remote sensing and geographic information systems to study urban quality of life and urban forest amenities. Ecol Soc 2004; 9(5).

[30] Lo CP, Faber BJ. Integration of Landsat Thematic mapper and census data for quality of life assessment. Rem Sens Env 1997; 62: 143-57.

[31] Emmanuel R. Urban vegetational change as an indicator of demographic trends in cities: The case of Detroit. Env Plan BPlan Des 1997; 24: 415-26.

[32] Pozzi F, Small C. Exploratory analysis of suburban land cover and population density in the U. S. A. Proceedings of Third International Symposium of Remote Sensing of Urban Areas; June 2002, Istanbul, Turkey; 2001.

[33] Imhoff ML, Lawrence WT, Stutzer DC, Elvidge CD. A technique for using composite DMSP/OLS "city lights" satellite data to map urban area. Rem Sens Env 1997; 61: 361-70.

[34] Sutton PC. A scale-adjusted measure of "Urban sprawl" using nighttime satellite imagery. Rem Sens Env 2003; 86: 353-69.

[35] Small C, Pozzi F, Elvidge CD. Spatial analysis of global urban extent from DMSP-OLS night lights. Rem Sens Env 2005; 96: 277 91.

[36] Sutton P, Costanza R. Global estimates of market and non-market values derived from nighttime satellite imagery, land cover, and ecosystem service valuation. Ecol Econ 2002; 41: 509-27.

[37] Doll CNH, Muller JP, Elvidge CD. Night-time imagery as a tool for global mapping of socioeconomic parameters and greenhouse gas emissions. AMBIO 2000; 29: 157-62.

[38] Amaral S, Monteiro AMV, Camara G, Quintanilha JA. DMSP/OLS night-time light imagery for urban population estimates in the Brazilian Amazon. Int Rem Sens 2006; 27: 855-70.

[39] Lu DS, Tian HQ, Zhou GM, Ge HL. Regional mapping of human settlements in southeastern China with multisensor remotely sensed data. Rem Sens Env 2008; 112: 3668-79.

[40] Jordan L. Eyes from above: remote sensing and virtual globes in spatial demography. Proceedings from meeting of the population association of America. New York; 2007.

[41] Stern M. Census from heaven? Population estimates with remote sensing techniques. PhD dissertation. Lund University 1985.

[42] Olorunfemi JF. Land-use and population - a linking model. Photo Eng Rem Sens 1984; 50: 221-7.

[43] Jensen JR, Cowen DC. Remote sensing of urban suburban infrastructure and socio-economic attributes. Phot Eng Rem Sens 1999; 65: 611-22.

[44] Li GY, Weng QH. Using landsat ETM plus imagery to measure population density in Indianapolis, Indiana, USA. Phot Eng RemSensing 2005; 71: 947-58.

[45] Liu XH, Clarke K, Herold M. Population density and image texture: A comparison study. Phot Eng Rem Sens 2006; 72: 18796.

[46] Caselli G, Vallin J, Wunsch GJ. Demography: analysis and synthesis. Academic press; 2006

[47] Dobson JE, Bright EA, Coleman PR, Durfee RC, Worley BA. LandScan: A global population database for estimating populations at risk. Phot Eng Rem Sens 2000; 66: 849-57.
[48] Balk D, Pozzi F. The distribution of people and the dimension of place: methodologies to improve the global estimation of urban extents. 25 March 2010: Available from: http: //sedac. ciesin org/gpw/docs/UR_paper_webdraft1. pdf.

[49] Balk D, Yetman G. The global distribution of population: evaluating the gains in resolution refinement. 25 March 2010 Available from: http: //sedac. ciesin. org/gpw/docs/gpw3_documentation_final. pdf.

[50] Hall O, Duit A, Caballero LNC. World Poverty, Environmental Vulnerability and Population at Risk for Natural Hazards. J Maps 2008; 151-60.

[51] Tobler WR. Satellite confirmation of settlement size coefficients. Area 1969; 1: 31-4.

[52] Sutton P, Roberts D, Elvidge C, Baugh K. Census from Heaven: An estimate of the global human population using night-time satellite imagery. Int J Rem Sens 2001; 22: 3061-76.

[53] Elvidge CD, Baugh KE, Hobson VR, et al. Satellite inventory of human settlements using nocturnal radiation emissions: A contribution for the global toolchest. Glo Cha Biol 1997; 3: 387-95.

[54] Elvidge CD, Baugh KE, Kihn EA, Kroehl HW, Davis ER, Davis CW. Relation between satellite observed visible-near infrared emissions, population, economic activity and electric power consumption. Int J Rem Sens 1997; 18: 1373-9.

[55] Doll CNH. Assesing the potential for quantitative estimation of socio-economic parameters from DMSP-OLS imagery. PhD dissertation. University of London 1998.

[56] Entwistle B, Walsh S, Rindfuss R, Chamratrihirong A. Landuse/land-cover dynamics, Nang Rong, Thailand. In: Liverman D, eds. People and pixels: Linking remote sensing and social sciences, National academy press, Washington, 1998.

[57] Qiu F, Woller KL, Briggs R. Modeling urban population growth from remotely sensed imagery and TIGER GIS road data. Phot Eng RemSens 2003; 69: 1031-42.

[58] Wilson DR. Air photo interpretation for archaeologists. B. T. Batsford; London, 1982.

[59] Lyons TR, Avery TE. Remote sensing: a handbook for archaelogists and cultural resource managers. Washington, 1977.

[60] Lyons TR, Avery TE. Remote sensing: a handbook for archaeologists and cultural resource managers. Supplement 7, Aerial and terrestrial photography for archaeologists. Washington, 1981.

[61] Wiseman J, El-Baz F. Remote sensing in Archaeology: Springer; 2007.

[62] Wiseman JR. An introduction to remote sensing in archaeology. Am J Arc 1987; 91: 322-

[63] Sever TL. Remote sensing in Chacocanyon, Poverty point, and Costa Rica. Am J Arc 1987; 92: 324-42

[64] Sheets P, Sever T. High-techwizardry. Arch 1988; 41: 28-35.

[65] Evans D, Pottier C, Fletcher R, et al. A comprehensive archaeological map of the world's largest preindustrial settlement complex at Angkor, Cambodia. Proc Natl Acad Sci USA 2007; 104: 14277-82.

[66] Saturno W, Sever T, Irwin D, Howell B, Garrison T. Putting us on the map: remote sensing investigation of the ancient Maya landscape. Springer: New York, 2007.

[67] Garrison TG, Houston SD, Golden C, Inomata T, Nelson Z, Munson J. Evaluating the use of IKONOS satellite imagery in lowland Maya settlement archaeology. J Arch Sci 2008; 35: 27707.

[68] Bitelli G, Zanni M. Use of Ikonos high resolution imagery in archaeology: The example of the ancient city of Bakchias in Egypt. Strat Eur Rem Sens 2005: 23-30.

[69] Masini N, Lasaponara R. Satellite-based recognition of landscape archaeological features related to ancient human transformation. J Geophys Eng 2006; 3: 230-5.

[70] Gallagher JM, Josephs RL. Using LiDAR to Detect Cultura Resources in a Forested Environment: an Example from Isle Royale National Park, Michigan, USA. Arch Pros 2008; 15: 187206.

[71] Dashora A, Lohani B, Malik JN. A repository of earth resource information - CORONA satellite programme. Curr Sci 2007; 92: 926-32.

[72] Dashora A, Sreenivas B, Lohani B, Malik JN, Shah AA. GCP collection for CORONA satellite photographs: Issues and methodology. J Ind Soc Rem Sens 2006; 34: 153-60. 
[73] Liverman DM, Cuesta RMR. Human interactions with the Earth system: people and pixels revisited. Earth Surf Proc Landform 2008; 33: 1458-71.

[74] Rindfuss RR, Walsh SJ, Turner BL, Fox J, Mishra V. Developing a science of land change: Challenges and methodological issues. Proc Natl Acad Sci USA 2004; 101(39): 13976-81.

[75] Reining P. Challenging desertification in West Africa: insights from Landsat into carrying capacity, cultivation and settlement sites in Upper Volta and Niger: Ohio University Press; 1979.

[76] Conant FP. Use of Landsat datain studies of human ecology. Curr Ant 1978; 19: 382-4.

[77] Conant FP. Landsat images for African rangelandinterpretation. Comp Graph World. 1982; 5: 42-3.

[78] Turner MD. Methodological reflections on the use of remote sensing and geographic information science in human ecological research. Hum Ecol 2003; 31: 255-79.

[79] Geist HJ, Lambin EF. What drives tropical deforestation? A metaanalysis of proximate and underlying causes of deforestation based on subnational case study evidence. LUCC report serie; no 4, 2001.

[80] Wood C, Skole D. Linking satellite, census, and survey data to study deforestation in the Brazilian Amazon. In: Liverman D, eds. People and Pixels: linking remote sensing and social sciences. National Academy Press; Washington, 1998.

[81] Pfaff ASP. What drives deforestation in the Brazilian Amazon? Evidence from satellite and socioeconomic data. J Env Econ Manag 1999 ; 37: 26-43.

[82] Dessie G, Kinlund P. Khat expansion and forest decline in Wondo Genet, Ethiopia. Geog Ann Ser BHum Geog 2008; 90B: 187-203.

[83] Lorena RB, Lambin EF. The spatial dynamics of deforestation and agent use in the Amazon. App Geog 2009; 29: 171-81.

[84] Lorena RB, Lambin EF. Linking spatial patterns of deforestation to land use using satellite and field data. In proceedings of International Geoscience and Remote Sensing Symposium; 2007: 3357-61.

[85] McGarigal K, Cushman S. Multivariate statistics for wildlife and ecology research. Springer: New York, 2000.

[86] Leitao AB, Miller J, Ahern J, McGarigal K. Measuring landscapes: a planners handbook. Island Press: Washington, 2006.

[87] Xie YC, Mei Y, Tian GJ, Xing XR. Socio-econornic driving forces of arable land conversion: A case study of Wuxian City, China. Glob Env ChanHum PolDim 2005; 15: 238-52.

[88] McCracken SD, Brondizio ES, Nelson D, Moran EF, Siqueira AD, Rodriguez-Pedraza C. Remote sensing and GIS at farm property level: Demography and deforestation in the Brazilian Amazon. Phot Eng Rem Sens 1999; 65: 1311-20.

[89] Hall O, Jansson U. HLUGIS Historical Land-Use GIS. In Proceedings of the Permanent European Conference for the Study of the Rural Landscape; 1996; Dublin.

[90] Long HL, Liu YS, Wu XQ, Dong GH. Spatio-temporal dynamic patterns of farmland and rural settlements in Su-Xi-Chang region:
Implications for building a new countryside in coastal China. Land Use Pol 2009; 26: 322-33.

[91] Witmer FDW, O'Loughlin J. Satellite Data Methods and Application in the Evaluation of War Outcomes: Abandoned Agricultural Land in Bosnia-Herzegovina After the 1992-1995 Conflict. Ann Ass Am Geog 2009; 99: 1033-44.

[92] Bhupendra J. Remote sensing from space: national and international security. One. The new security debate. Disarmament forum 1999: 31-40.

[93] Maathius BHP. Remote sensing detection of minefields. Geoc int 2003; 18: 51-60.

[94] Howes DH. The mapping of agricultural disaster with Landsat MSS data: the disruption of Nicaraguan agriculture. PhD dissertation. Milwaukee: University of Milwaukee 1979.

[95] Smith JH. Land cover changes in the Bosawas region of Nicaragua1986-1996. PhD dissertation. Athens, GA: University of Georgia 1998.

[96] Cosgrove RB, Milanfar P, Kositsky J. Trained detection of buried mines in SAR images via the deflection-optimal criterion. Trans Geosci Rem Sens 2004; 42: 2569-75.

[97] Zare A, Bolton J, Gader P, Schatten M. Vegetation mapping for landmine detection using long-wave hyperspectral imagery. Trans Geosci Rem Sens 2008; 46: 172-8.

[98] Ebener S, Murray C, Tandon A, Elvidge CC. From wealth to health: modelling the distribution of income per capita at the subnational level using night-time light imagery. Int Health Geog 2005; $4: 5$.

[99] Toenges-Schuller N, Stein O, Rohrer F, Wahner A, Richter A, Burrows JP, et al. Global distribution pattern of anthropogenic nitrogen oxide emissions: Correlation analysis of satellite measurements and model calculations. J Geophys Res-Atm 2006; 111: D5.

[100] Cinzano P, Falchi F, Elvidge CD. The first World Atlas of the artificial night sky brightness. Month Not Roy Astr Soc 2001; 328 : 689-707.

[101] Waluda CM, Yamashiro C, Elvidge CD, Hobson VR, Rodhouse PG. Quantifying light-fishing for Dosidicus gigas in the Eastern Pacific using satellite remote sensing. Rem Sens Env 2004; 91: 129-33.

[102] Kohiyama M, Hayashi H, Maki N, Higashida M. Early damaged area estimation system using DMSP-OLS night-time imagery. Int J Rem Sens 2004; 25: 2015-36.

[103] Kohiyama M, Yamazaki F. Image fluctuation model for damage detection using middle-resolution satellite imagery. Int J Rem Sens 2005; 26 : 5603-27.

[104] De Souza CR, Zullo J, Elvidge C. Brazil's 2001 energy crisis monitored from space. Int J Rem Sens 2004; 25: 2475-82.

[105] Longley PA. Geographical Information Systems: will developments in urban remote sensing and GIS lead to 'better' urban geography? Prog Hum Geog 2002; 26: 231-9.

Received: December 28, 2009

Revised: March 20, 2010

Accepted: March 26, 2010

(c) Ola Hall; Licensee Bentham Open.

This is an open access article licensed under the terms of the Creative Commons Attribution Non-Commercial License (http://creativecommons.org/licenses/by-nc/3.0/) which permits unrestricted, non-commercial use, distribution and reproduction in any medium, provided the work is properly cited. 